\title{
Arkansas Groundwater-Quality Network
}

\section{A Web Map Interface for Data Retrieval}

Arkansas is the fourth largest user of groundwater in the United States, where groundwater accounts for two-thirds of the total water use. Groundwater use in the State increased by 510 percent between 1965 and 2005 (Holland, 2007). The Arkansas Groundwater-Quality Network is a Web map interface (http://ar.water.usgs.gov/wqx) that provides rapid access to the U.S. Geological Survey's (USGS) National Water Information System (NWIS) and the U.S. Environmental Protection Agency's (USEPA) STOrage and RETrieval (STORET) databases of ambient water information. The interface enables users to perform simple graphical analysis and download selected water-quality data.

\section{Description of National Water Information System and Storage and Retrieval Databases}

NWIS is part of the USGS's program for disseminating water data collected over the last $100+$ years. The system is a distributed network of computers and fileservers that stores and retrieves water data at approximately 1.5 million locations nationwide (U.S. Geological Survey, 2013). NWIS includes approximately 57,000 groundwater locations in Arkansas, although only water-level data are available for many of these locations.

The STORET Data Warehouse is USEPA's national repository for water-quality, biological, and physical data collected by Federal and State agencies, tribes, local governments, academic groups, watershed and volunteer monitoring organizations, and the public. STORET is a nationally consistent framework for water-quality data that enables users to share data across multiple organizations (U.S. Environmental Protection Agency, 2013).

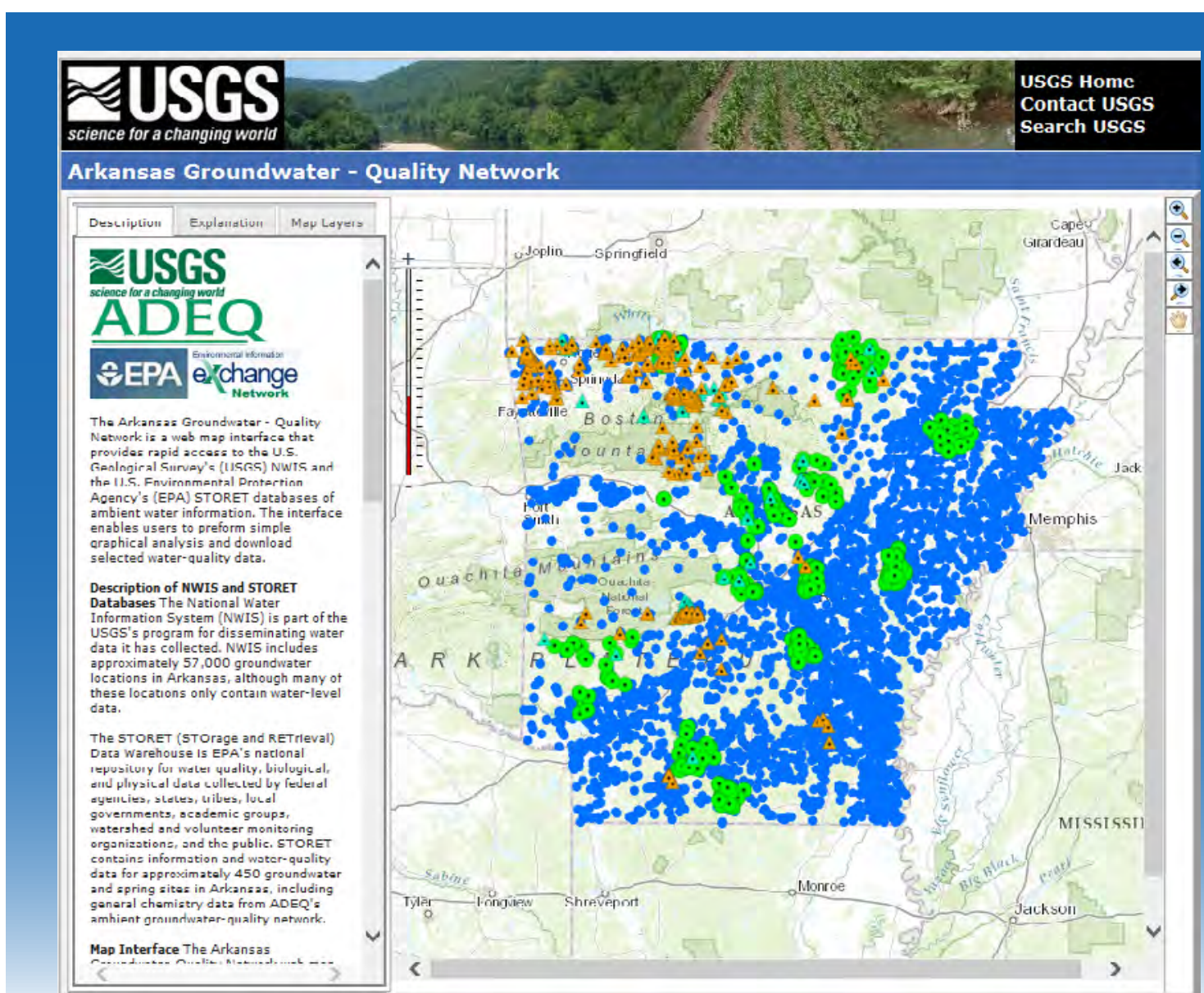

STORET contains information and water-quality data for approximately 450 groundwater and spring locations in Arkansas, including general chemistry data from the Arkansas Department of Environmental Quality's ambient groundwater-quality network.

\section{Data Retrieval}

The Arkansas Groundwater-Quality Network Web map interface uses the geospatial capabilities of ArcGIS to retrieve data directly from NWIS and STORET using the National Water Quality Monitoring Council's Water Quality Portal (National Water Quality Monitoring Council, 2013). The Portal provides data in a consistent format utilizing the common nomenclature known as the Water Quality Exchange (WQX) to output data from both NWIS and STORET. The map interface allows users to choose an area of interest, retrieve available groundwater-quality data, view and conduct simple graphical analysis, and download the selected data. 


\section{Explanation}

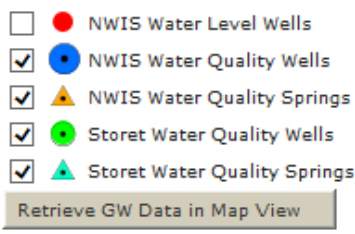

Longitude:

Within: MILES Retrieve GW Data in radius

Note: This accepts both decimal degree (DD) and degree, minute and second (DMS) notations.

I.E. (DD): Latitude: 32.551967 I.E. (DMS): Latitude: 323333
Latitude:

Well and spring sites of interest may be selected geographically using the map interface or by defining a point location and radius around the point. To select sites using the map interface, the user first selects the site type of interest, wells or springs, or both, and the database, STORET or NWIS, or both, from the checkbox menu found within the "Sites" tab in the map interface menu along the left side of the page. The user may also change the base map background by selecting the desired base map from a list found within the "Map Layers" tab, also within the map interface menu. Using the navigation tools along the right side of the page, the user zooms into the area of

interest, and clicks the "Retrieve GW Data in Map View" button found within the "Sites" tab. Additionally, users may select well and spring locations of interest by entering the latitude and longitude, in decimal degrees or degrees, minutes, and seconds; a search radius, in miles; and clicking the "Retrieve GW Data in radius" button in the sites tab. After the retrieve data buttons are clicked, the data management page is opened within a new browser window.

\section{Data Management}

The data management page provides users with the opportunity to select and unselect sites, perform simple graphical analyses, and view and download data. Users may further refine site selection by using the pull down menu to the right of the "Monitoring Location Identifier" heading and clicking the desired check-boxes associated with the listed sites. The pulldown menu to the right of the "Action" heading provides users with the opportunity to perform simple graphical analysis, preview selected site data, and download selected site data. Graphical analyses of selected site data are limited to equivalent concentrations of the cations and the anions, in milliequivalents per liter or milligrams per liter. Available graphical analyses include pie and bar charts, along with
Stiff diagrams. Selected site data may be viewed before downloading by clicking the radio button associated with "PREVIEW DATA (web)." Selected site data may be downloaded in a tab delimited, comma delimited, or Excel format by clicking the appropriate radio button associated with the desired format.

\section{Benefits Scientists and Managers}

The Arkansas Groundwater-Quality Network provides scientists, engineers, managers, and the public improved access to groundwater-quality information. The network decreases the time needed to make groundwater-quality interpretations, assists in making accurate groundwater-quality interpretations, and ultimately enhances decision-making processes.

\section{References}

Holland, T.W., Water use in Arkansas, 2005: U.S. Geological Survey Scientific Investigations Report 2007-5241, 32 p.

National Water Quality Monitoring Council, 2013, Water quality portal: Web page, accessed January 10, 2013, at http://www.waterqualitydata.us/.

U.S. Environmental Protection Agency, 2013, STORET/WQX: Home: Web page, accessed January 10, 2013, at http://www.epa.gov/storet/.

U.S. Geological Survey, 2013, NWISWeb: New site for the Nation's water data: U.S. Geological Survey Fact Sheet 128-02, 2 p. (Also available at http://pubs. usgs.gov/fs/fs-128-02/.)

The Arkansas Groundwater-Quality Network web page was developed by the USGS Arkansas Water Science Center in cooperation with the Arkansas Department of Environmental Quality using funds provided by a USEPA Exchange Network grant.

\section{-By Aaron L. Pugh, U.S. Geological Survey, Barry T. Jackson, U.S. Geological Survey, and Roger Miller, Arkansas Department of Environmental Quality}

Any use of trade, produce, or firm names is for descriptive purposes only and does not imply endorsement by the U.S. Government.

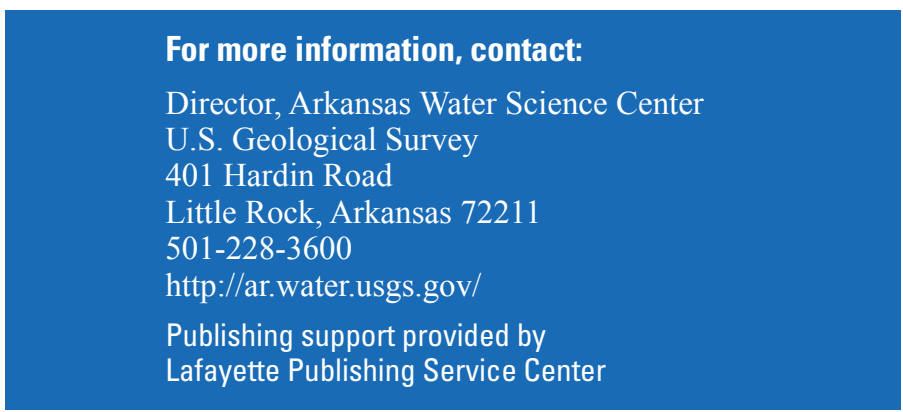

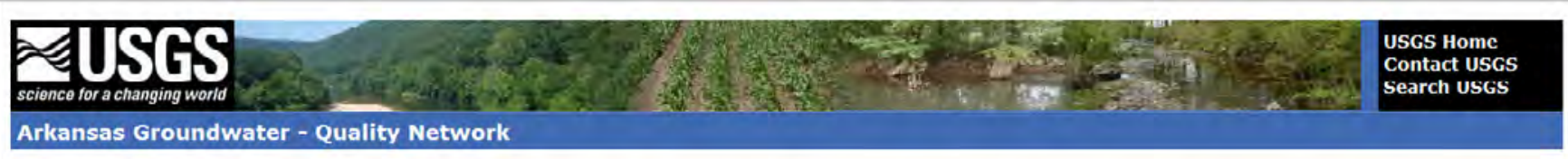

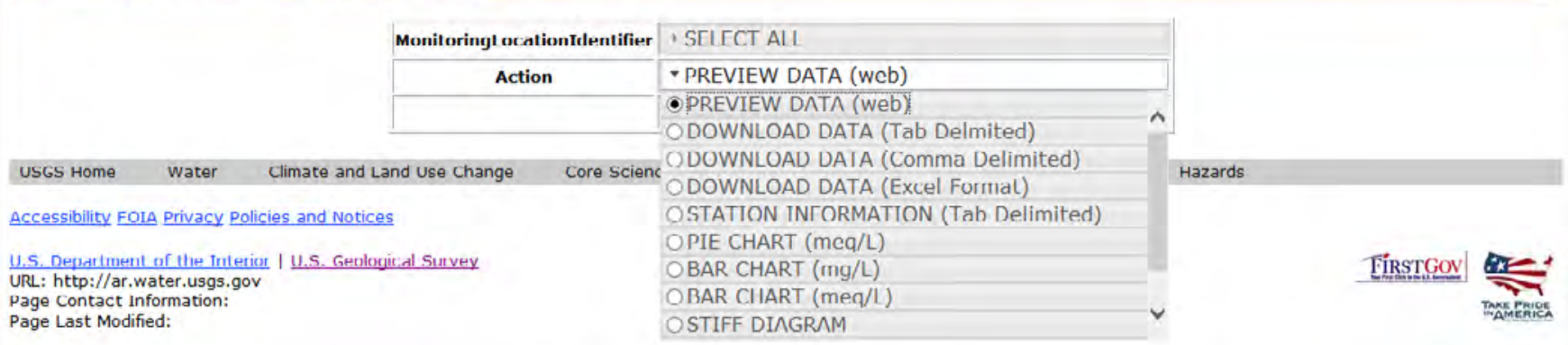

